\title{
Article \\ Electromagnetic Field Analysis and Design of a Hermetic Interior Permanent Magnet Synchronous Motor with Helical-Grooved Self-Cooling Case for Unmanned Aerial Vehicles
}

\author{
Hae-Sol Lee ${ }^{1,2}{ }^{\mathbb{D}}$, Myeong-Hwan Hwang ${ }^{1}$ and Hyun-Rok Cha ${ }^{1, *}$ \\ 1 EV Components \& Materials R\&D Group, Korea Institute of Industrial Technology, \\ 6 Cheomdan-gwagiro 208 beon-gil, Buk-gu, Gwangju 61012, Korea; eddylee0319@gmail.com (H.-S.L.); \\ han9215@kitech.re.kr (M.-H.H.) \\ 2 Robotics and Virtual Engineering, Korea University of Science and Technology, Daejeon 34113, Korea \\ * Correspondence: hrcha@kitech.re.kr; Tel.: +82-62-600-6212
}

\section{check for}

updates

Citation: Lee, H.-S.; Hwang, M.-H.; Cha, H.-R. Electromagnetic Field Analysis and Design of a Hermetic Interior Permanent Magnet

Synchronous Motor with

Helical-Grooved Self-Cooling Case for Unmanned Aerial Vehicles. Appl. Sci. 2021, 11, 4856. https://doi.org/ 10.3390/app11114856

Academic Editor:

George Nikolakopoulos

Received: 2 May 2021

Accepted: 19 May 2021

Published: 25 May 2021

Publisher's Note: MDPI stays neutral with regard to jurisdictional claims in published maps and institutional affiliations.

Copyright: (c) 2021 by the authors. Licensee MDPI, Basel, Switzerland. This article is an open access article distributed under the terms and conditions of the Creative Commons Attribution (CC BY) license (https:/ / creativecommons.org/licenses/by/ $4.0 /)$.

\begin{abstract}
As unmanned aerial vehicles expand their utilization and coverage, research is in progress to develop low-weight and high-performance motors to efficiently carry out various missions. An electromagnetic field interior permanent magnet (IPM) motor was designed and analyzed in this study that improved the flight performance and flight duration of an unmanned aerial vehicle (UAV). The output power and efficiency of a conventional commercial UAV motor were improved by designing an IPM motor of the same size, providing high power output and high-speed operation by securing high power density, wide speed range, and mechanical stiffness. The cooling performance and efficiency of the drive motor were improved without requiring a separate power source for cooling by introducing the helical-grooved self-cooling case, which has a low heat generation structure. Furthermore, the motor is oil-cooled through rotating power without a separate power source, reducing the weight of the UAV. The heat dissipation characteristics were verified by fabricating a prototype and taking actual measurements to verify the validity of the heat dissipation characteristics. The results of this study are expected to improve the flight duration and performance of UAVs and contribute to the efficiency of the design of a UAV drive motor.
\end{abstract}

Keywords: interior permanent magnet; unmanned aerial vehicle; finite element method; drive motor efficiency; heat dissipation characteristics

\section{Introduction}

Unmanned aerial vehicles (UAVs) are increasingly being used for civilian purposes such as logistics, transportation, traffic relations, and security. Recently, their application range has been expanding; UAVs, initially operated only for military uses, have started to be used for various purposes such as aerial photography and pesticide application. The application range of UAVs will expand because they do not entail inherent safety risks and high expenses compared to a much larger, manned aircraft. In recent years, China has emerged as a leader in the commercial UAV market, along with technology powerhouses such as the United States and Europe [1-3].

The technology for creating a UAV motor with high power output and high efficiency has emerged to enlarge the size of the UAV platform, because the weight of the UAV increases owing to the use of various functions of the UAV platform. Therefore, most UAV motors adopt permanent-magnet synchronous motors, in which surface permanent magnet motors are most commonly used. Electric motors for operating UAVs significantly affect flight performance. The flight distance, efficiency, torque, vibration, maximum speed, and acceleration forces are determined or changed depending on the drive motor. 
An interior permanent-magnet (IPM) synchronous motor has a structure in which a permanent magnet is embedded in the rotor. An IPM synchronous motor has the advantage of being able to obtain a large torque per unit volume because it has both an alignment torque owing to a permanent magnet, and a reluctance torque owing to the difference in the $d-q$-axis magnetic resistance. In addition, there is a substantial difference in the $d-q$-axis inductance distribution inside the rotor because the magnetic properties of the embedded permanent magnet are similar to those of a void. The rotor can have a wide range of variable-speed driving characteristics through field weakening control in proportion to the saliency ratio. Therefore, torque can be augmented because of the advantages of high output power and high-speed operation by securing high power density, wide speed range, and mechanical stiffness, which are the characteristics of an IPM motor. Accordingly, the study aimed to design and analyze UAV motors with the IPM method based on the hypothesis that high-power results can be obtained when these are used in UAV motors. Furthermore, we plan to design a method to minimize rotational interference from external foreign substances by developing a hermetic design. A self-oil cooling-type low heat generation structure supplementing the vulnerability of a hermetic structure to heat generation was designed and is proposed [4-6].

Demand for a low heat generation design that can improve flight duration and reliability increases as the output power of the UAV motor increases with the design of the IPM synchronous motor. The self-heating increases as the output power per unit weight of the motor increases, which is directly related to the increase in the internal temperature. This adversely affects the overall performance because it causes internal thermal deterioration and reduces the lifetime. Various cooling methods, such as installing a coolant channel within the housing or directly spraying cooling oil into the motor, have been studied to improve the internal temperature environment of the motor. However, the size and installation of the motor are limited, because this approach requires an additional device to cool the motor. Cooling technology, which is the core technology of heat dissipation design, is closely associated with high efficiency, miniaturization, high performance, and motor durability. Meanwhile, cooling methods for effectively discharging or distributing the generated heat can be classified into three types according to the fluid used. Typical cooling methods include an air-cooled type that cools the motor housing or the inside of the motor through forced convection by using air [7], a water-cooled type that cools by flowing coolant to the motor housing or internal parts [8], and oil cooling by directly spraying oil to the heat source inside the motor, considering oil insulation and cooling characteristics [9].

Recently, studies on an oil cooling method using oil with good insulation characteristics have been actively conducted to satisfy the limitations of size and weight in high-power motors. Ponomaerv et al. [10] compared a motor cooling system using oil by considering a simplified computational fluid model that used periodic conditions and a one-dimensional parameter model. Davin et al. [11] investigated the cooling effect according to the spraying speed by conducting an experiment varying the spraying speed of the oil. Moreover, Nategh et al. [12] explained the cooling effect due to oil through a computational fluid model that incorporated a one-dimensional heat transfer model. Lim et al. [13] performed a thermal performance evaluation under continuous rated conditions using a three-dimensional flow analysis model for an in-wheel motor to which an oil cooling method was applied. The analysis results were then reflected in the design of the motor. However, a few studies have been conducted regarding cooling the motor using the rotational force of the motor itself without an external power source, among the studies on the cooling analysis of the motor to which the oil cooling method was applied. The range of application of the UAV will be further expanded if such a method is introduced to a $\mathrm{UAV}$, because flight duration can be increased by reducing the weight of the aircraft, and the motor performance can be increased through a low heat generation design.

Therefore, in this study, a hermetic IPM motor was designed and analyzed using the 3D finite element method. A self-oil cooling structure was designed and proposed to develop a motor housing with a low heat generation structure. A prototype was fabricated 
according to the design, and experiments regarding the heat dissipation characteristics experiment were conducted to compare and analyze the prototype and the conventional air-cooled motor. The optimized self-oil cooling structure and shape were determined using a detailed shape design. The results of this study are expected to improve the flight duration and performance of UAVs and contribute to the efficiency of the design of the $\mathrm{UAV}$ drive motor.

\section{Fluid Flow Analysis Governing Equations}

For the computational analysis of cooling performances, a conjugate heat transfer analysis could be applied, considering both the solid heat conduction of the inner and outer pipes and the convective heat transfer of the cooling oil. The continuity equation and the Reynolds averaged Navier-Stokes (RANS) equation, which are the conservation of mass and momentum equations, respectively, were used as the governing equations for fluid flow analysis, as in [14]. The realizable k $\epsilon$ was applied to the turbulence model [15].

$$
\begin{gathered}
\frac{\partial u_{i}}{\partial \mathrm{x}_{i}}=0, \\
\frac{\partial}{\partial \mathrm{t}}\left(\rho u_{i}\right)+\frac{\partial}{\partial x_{j}}\left(\rho u_{i} u_{j}\right)=-\frac{\partial \rho}{\partial x_{i}}+\frac{\partial}{\partial x_{j}}\left[\mu\left(\frac{\partial u_{i}}{\partial x_{j}}+\frac{\partial u_{j}}{\partial x_{i}}-\frac{2}{3} \delta_{i j} \frac{\partial u_{k}}{\partial x_{k}}\right)\right]+\frac{\partial}{\partial x_{j}}\left(\partial \partial \overline{u_{i}^{\prime} u_{j}^{\prime}}\right)-\partial \partial \overline{u_{i}^{\prime} u_{j}^{\prime}} \\
=\mu_{t}\left(\frac{\partial u_{i}}{\partial x_{j}}+\frac{\partial u_{j}}{\partial x_{i}}\right)-\frac{2}{3}\left(\partial \partial+\mu_{t} \frac{\partial u_{k}}{\partial x_{k}}\right) \delta_{i j} \frac{\partial}{\partial t}(\rho k)+\frac{\partial}{\partial x_{j}}\left(\rho k \mu_{j}\right) \\
=\frac{\partial}{\partial x_{j}}\left[\left(\mu+\frac{u_{t}}{\sigma_{t}}\right) \frac{\partial k}{\partial x_{k}}\right]+G_{k}-\rho \epsilon \\
\frac{\partial}{\partial \mathrm{t}}(\rho \epsilon)+\frac{\partial}{\partial x_{j}}\left(\rho \epsilon u_{j}\right)=\frac{\partial}{\partial x_{j}}\left[\left(\mu+\frac{\mu_{t}}{\sigma_{\epsilon}}\right) \frac{\partial \epsilon}{\partial x_{j}}\right]+\rho C_{1} S_{\epsilon}-\rho C_{2} \frac{\epsilon^{2}}{k+\sqrt{v \epsilon}}, \\
C_{1}=\max \left[0.43, \frac{\eta}{\eta+5}\right], \eta=S \frac{k}{\epsilon}, S=\sqrt{2 S_{i j} S_{i j}}, \mu_{t}=\rho C_{\mu} \frac{k^{2}}{\epsilon},
\end{gathered}
$$

where $C_{2}, \sigma_{k}, \sigma_{\epsilon}$, and $C_{\mu}$ are turbulence model constants with values of 1.9, 1.0, 1.2, and 0.09 , respectively. The energy equation was used for heat transfer analysis as follows: Equation (5) is the fluid convective heat transfer equation, and Equation (6) is the heat transfer equation inside the solid.

$$
\begin{gathered}
\frac{\partial}{\partial \mathrm{t}}(\rho E)+\frac{\partial}{\partial x_{i}}\left(\rho u_{i} E\right)+\frac{\partial}{\partial x_{i}}\left(u_{i} p\right)=\frac{\partial}{\partial x_{j}}\left(k_{e f f} \frac{\partial \mathrm{T}}{\partial x_{j}}\right)+S_{h}, \\
\frac{\partial}{\partial x_{i}}\left(\rho_{\text {solid }} E\right)=\frac{\partial}{\partial x_{j}}\left(k_{\text {solid }} \frac{\partial \mathrm{T}}{\partial x_{j}}\right)+S_{h \prime} \\
k_{e f f}=k+\frac{c_{p} \mu_{t}}{P r_{t}}
\end{gathered}
$$

where $E$ denotes the total amount of energy, $k_{e f f}$ denotes the effective thermal conductivity, and $P r_{t}$ denotes the turbulent Prandtl number, which is 0.85. The SIMPLEC technique was applied to obtain the pressure field [16]. An incompressible flow was assumed, and the second-order upstream difference scheme was applied to all spatial differences [17].

\section{Design and Electromagnetic Field Analysis of IPM Synchronous Motor}

\subsection{Stator Analysis Model Specification}

A motor was designed using JMAG, an electromagnetic field analysis program, and its performance was verified through no-load and load simulations in this study. The design of the IPM motor was performed to satisfy the desired characteristics by solving the magnetic phenomenon based on Maxwell's equation [18].

The stator model specifications of the IPM motor used in this study are listed in Table 1. A total of 36 stator slots and a rated DC voltage of $67.882 \mathrm{~V}$ were considered in the 
main specification. The analysis was performed by equally inputting all currents according to the speed. The motor-rated maximum current value was $80 \mathrm{~A}$. A cross-sectional diagram of the 36 slots is shown in Table 1. The outer diameter of the interior permanent magnet motor stator was $81 \mathrm{~mm}$. The counter-electromotive force waveform in the stator was designed in a distribution area for a sinusoidal wave to be formed. Moreover, it was designed not to exceed $45 \%$ at $43.69 \%$ by considering the insulation thickness because the fill factor for winding was reported to be below $45 \%$. In addition, a winding method of winding six $0.4 \mathrm{~mm}$ coils for 10 turns was applied to reduce the current density.

Table 1. Parameters of the stator.

\begin{tabular}{cccc}
\hline Winding Diagram & Parameters & Unit & Value \\
\hline & Number of Slot & Slot & 36 \\
& Number of Pole & Pole & 42 \\
& Outside Diameter & $\mathrm{mm}$ & 81 \\
& Inside Diameter & $\mathrm{mm}$ & 60 \\
& Stack Length & $\mathrm{mm}$ & 20 \\
& Air Gap & $\mathrm{mm}$ & 0.4 \\
& Number of Turns & Turns & 10 \\
& Number of Strands & Turns & 6 \\
& Phase Resistance & $\mathrm{m} \Omega$ & 0.202 \\
& Slot Fill Factor & $\%$ & 43.69 \\
& Rated Mechanical Power & $\mathrm{W}$ & 2000 \\
& Rated Rotational Frequency & $\mathrm{Hz}$ & 60 \\
\hline
\end{tabular}

Typically, interference between the permanent magnet and the slot in conventional commercial motors is present. This interference deteriorates the magnetic flux and strength of the magnet and provides a space for flux to flow between the magnets. Therefore, the design was focused on removing the space of flux between magnets and creating the flow of magnetic flux sound by opening the surface of the permanent magnet in the slot direction.

Through JMAG, we performed a simulation to measure the motor output according to the inverter vector control of the IPMSM. The combination of the $q$-axis and $d$-axis current has a point that can produce maximum torque with a minimum stator current and is referred to as the maximum torque per ampere (MTPA), which uses MTPA control to control the motor with this combination of $q$-axis and $d$-axis current.

\subsection{Electromagnetic Field Analysis and Results}

The electromagnetic field analysis was performed by connecting a current source and equally inputting a constant current according to the speed. The analysis range was the main rotation section, which was between 3500 and $4500 \mathrm{rpm}$. A comparative analysis was performed at the current phase angle of $40^{\circ}$ to analyze the maximum torque characteristics because the maximum torque has been reported which is generally shown at a current phase angle of $35-45^{\circ}$ if the phase angle is controlled [19].

Figure 1 shows the analysis model for electromagnetic analysis and flux flow during simulation. IPMSM generates maximum torque because it adds magnetic torque from permanent magnets and reluctance torque from magnetic resistance differences depending on rotor position. Therefore, it is designed to use both magnetic torque and reluctance torque using SKD11 between magnets, using a magnesium alloy that allows flux to flow through the stator. 

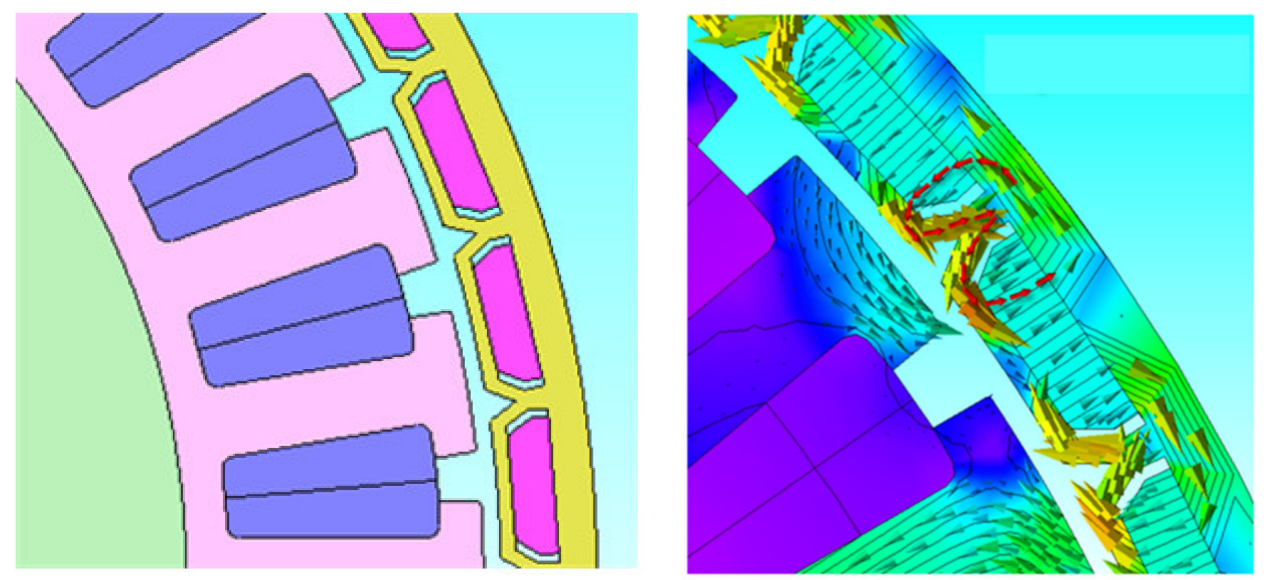

Figure 1. Analysis model and electromagnetic flux of the IPM motor.

No-load simulation was performed through an electromagnetic analysis program to analyze cogging torque and back-EMV, and Figure 2 represents the analysis results. The cogging torque was measured at $0.00363 \mathrm{Nm}_{\text {peak-peak }}$ at $10 \mathrm{rpm}$, and back-EMV was measured at $5.58 V_{\text {ph_rms }}$ at $1000 \mathrm{rpm}$.

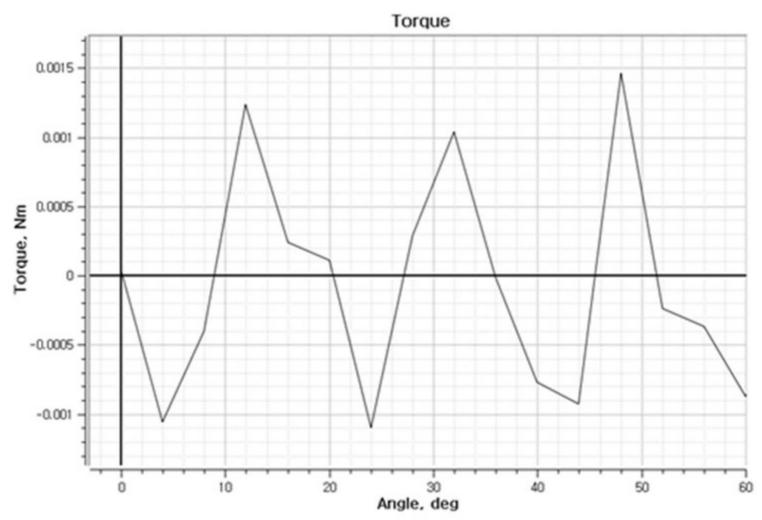

(a)

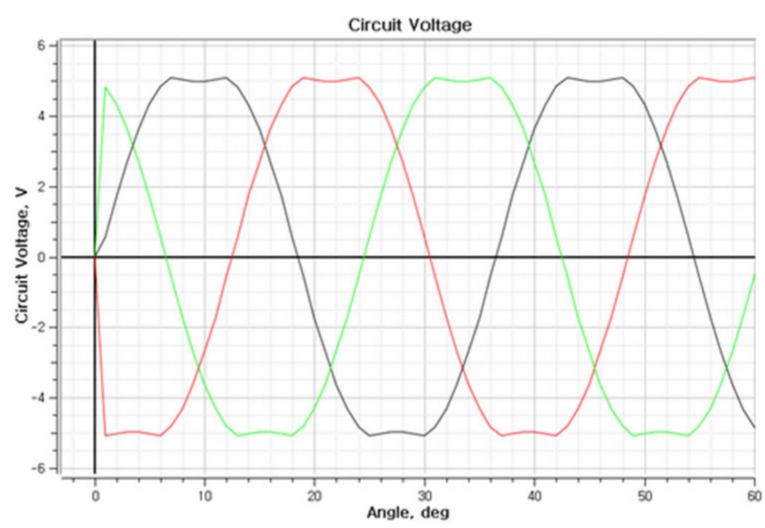

(b)

Figure 2. No-load analysis results of the IPM motor. (a) Cogging torque at $10 \mathrm{rpm}$; (b) Back-EMV at $1000 \mathrm{rpm}$.

Figure 3 shows the motor performance with respect to the rotational speed when the motor is driven in the main driving section. It is challenging to exceed an output power of $2000 \mathrm{~W}$ in similar-sized surface permanent magnet commercial motors. However, this model has an output power of $2604 \mathrm{~W}$, which is superior to conventional commercial motors because IPM motors with higher protrusion ratios $\left(L_{d}>L_{q}\right)$ compared to SPM motors integrate the reluctance torque of the motor to increase efficiency and torque. It was also found that the efficiency was $90.7 \%$, which is the maximum value at $4500 \mathrm{rpm}$. Therefore, the utility and applicability are high because the flight duration and distance of the UAV are extended; it is easy for the motor to rotate at high speed. Moreover, the output power and efficiency of the proposed motor improve compared to those of the conventional SPM motor. 


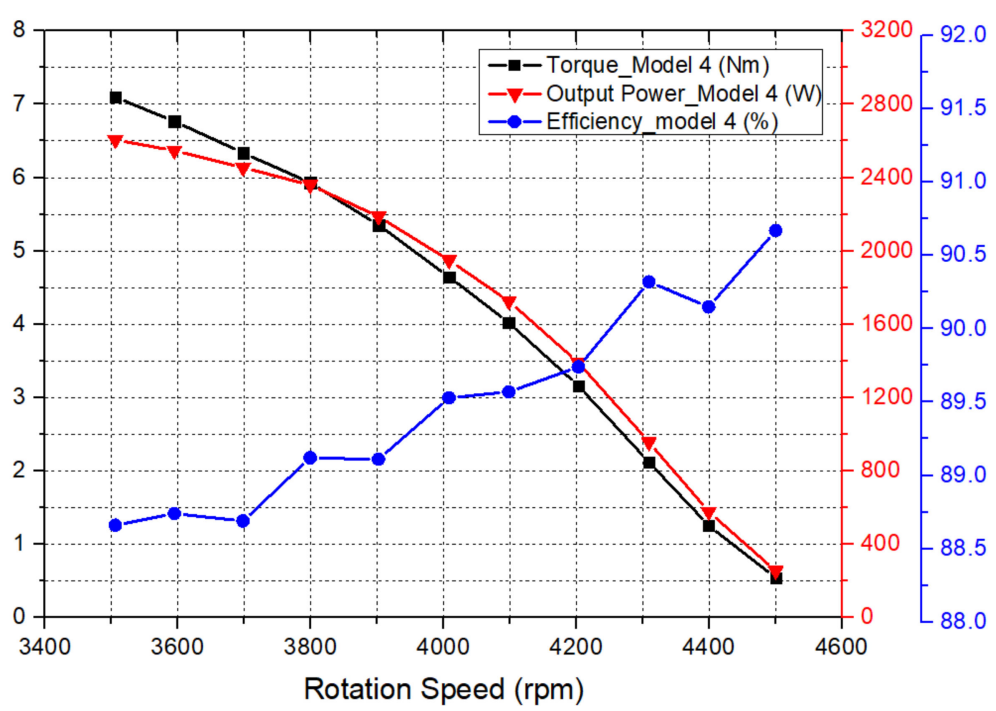

Figure 3. Electromagnetic field analysis result of the IPM motor.

\section{Design of the Helical-Grooved Self-Cooling Case}

A motor generally requires a device for cooling the motor because the core and coil have a high possibility of failure due to heat generation. Therefore, a conventional watercooled cooling motor is used to cool the motor, injecting cooling oil into the inside and outside of the housing and circulating the cooling oil. However, a conventional watercooled cooling motor requires a separate external power source to circulate the cooling oil. In particular, the conventional water-cooled cooling motor cooled the motor using an external pump, circulating cooling oil through the power of the pump. Likewise, the installation cost and the maintenance cost for cooling the motor increase because the conventional water-cooled cooling motor requires a pump, which is a separate power source.

In this study, technology for cooling the motor enabling the cooling oil to flow up the outer wall of the rotor was proposed. In particular, a case surrounding the outer wall of the rotor was fabricated, and a helix groove was formed on the outer wall of the rotor to form an upward swirling flow of cooling oil at the bottom of the outer housing when the outer rotor rotated. In other words, the motor can be cooled by circulating cooling oil without a separate power source. The intention was to determine the effect of the core and coil, which are the main causes of motor heat generation, and undergo cooling and heat dissipation due to the cooling oil. The diffusion rate, $v$, of a gas in a one-dimensional flow field with a number density gradient is expressed as follows:

$$
v=-D \frac{1}{n} \frac{d n}{d x}
$$

where $D$ is the diffusion coefficient. For free molecular flow, the diffusion coefficient $D_{m}$ in the helical groove can be derived as follows. First, the throughput $Q$ through helical groove is expressed as shown in the following equation [20].

$$
Q=C_{1} \frac{8}{3}\left(\frac{R T}{2 \pi}\right)^{\frac{1}{2}} \frac{w^{2} h^{2}}{w+h}\left(-\frac{d p}{d x}\right),
$$

where $C_{1}$ denotes a correction factor according to the aspect ratio of the cross-section, $R$ denotes the gas constant, $T$ denotes the absolute temperature, and $w$ and $h$ are the width and height of the helical groove, respectively. The diffusion velocity $v_{m}$ for the free 
molecular flow can be derived by dividing Equation (9) by the product of pressure and cross-sectional area, $p A$, and using the equation of state, $p=n k T$.

$$
\frac{Q}{p A}=v_{m}=-D_{m} \frac{1}{n} \frac{d n}{d x},
$$

where the diffusion coefficient is $D_{m}=2 C_{1} v_{0} w h /\{3(w+h)\}$, and the molecular average velocity is $v_{0}=\sqrt{8 R T / \pi}$. The conductance, $C$, in the helical groove is as follows:

$$
C=3.54 \times 10^{-2} C_{2} \frac{w^{2} h^{2}}{\mu L} \bar{p},
$$

where $\mu, L, p$, and $C_{2}$ denote the viscosity coefficient, length of the pipe, average pressure at the inlet and outlet, and correction coefficient according to the aspect ratio of the section, respectively. $C$ can be expressed as the product of the diffusion velocity $v_{v}$ and the cross-sectional area $A$ in the viscous region; therefore, Equation (14) can be ultimately summarized for $v_{v}$ as follows:

$$
\begin{aligned}
v_{v}= & -C_{2} \frac{w h}{28.249 \mu}\left(-\frac{d p}{d x}\right) \\
& =-D_{v} \frac{1}{n} \frac{d n}{d x},
\end{aligned}
$$

where $D_{v}=C_{2} v_{0} w h /(35.967 \lambda)$.

Figure 4 shows the structure where the helix structure of the helical-grooved selfcooling case is unfolded in the circumferential direction. It is simplified by rotating the motor at a speed $u$ along the helix groove on the outer wall of the rotor. The following equation can be expressed if the leakage flow rate per area is $q$, as gas leaks through the gap $\delta$, as shown in Figure 4.

$$
u_{d}-\frac{q}{n}=\left(D_{m} f_{m}+D_{v} f_{v}\right) \frac{1}{n} \frac{d n}{d x}
$$

where $u_{d}$ is as follows:

$$
u_{d}=u \frac{w}{2(w+h)} \cos \alpha
$$
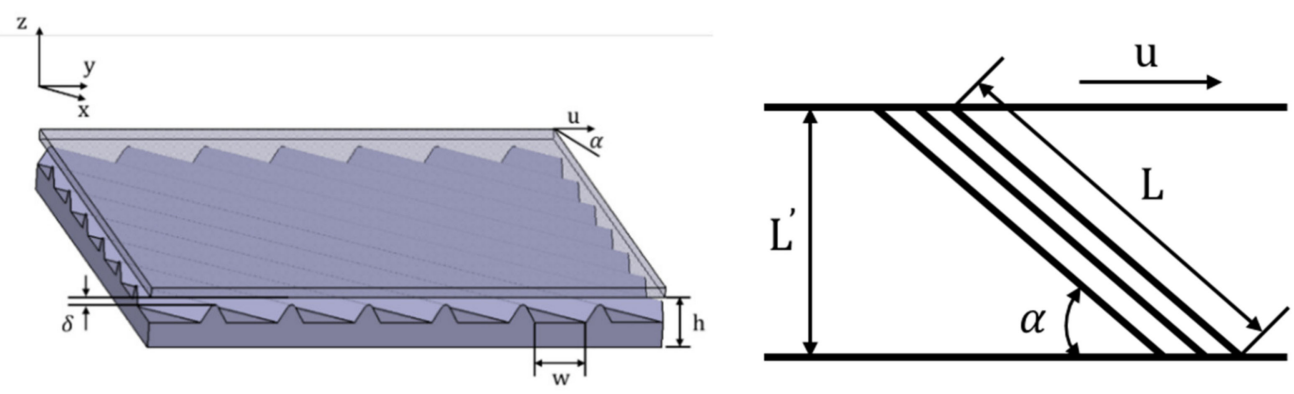

Figure 4. Helical-grooved self-cooling case.

The leakage flow rate $q$ in the equation is assumed as shown in Equation (15).

$$
q=n_{2} u_{d} \frac{A_{l}}{A_{p}}
$$

where $A_{l}, A_{p}$, and $n_{2}$ denote the leakage area, area of the flow path, and water density at the outlet, respectively. The leakage amount was calculated by considering that leakage is 
continuously found from the inlet to the outlet through the distance outlet $\delta$ between the rotor and stator, as shown in Figure 2.

$$
q=\int_{0}^{L} n u \frac{\delta L \sin \alpha}{2 A_{p}(L+\delta)} d x
$$

Therefore, Equation (13) is as follows:

$$
u_{d} n\left(1-b \frac{u L}{2 u_{d}(L+\delta)} \frac{\int_{0}^{L} n d x}{n}\right)=\frac{v_{0}}{\sigma h}\left\{C_{1} \frac{2 w h}{3(w+h)}\right\} \times\left\{\frac{\lambda}{\lambda+h}+\frac{C_{2}\left(\frac{1}{A R}+1\right)}{23.978 C_{1}} \frac{h}{\lambda} \frac{h}{\lambda+h}\right\} \frac{d y}{d x},
$$

where $A R$ denotes the aspect ratio $\frac{h}{w}$ of the cross-section.

Substituting $y=h / \lambda$, Equation (17) can be summarized as follows:

$$
\frac{u_{d}}{v_{0}}=\frac{2 C_{1} w h}{3(w+h)} \frac{\left(\frac{1}{1+y}+C_{3} \frac{y^{2}}{1+y}\right) \frac{d y}{d x}}{\sigma h n\left(1-b \frac{u L}{2 u_{d}(L+\delta)} \frac{\int_{0}^{L} n d x}{n}\right)},
$$

where $C_{3}$ is as follows:

$$
C_{3}=\frac{C_{2}\left(\frac{1}{A R}+1\right)}{23.978 C_{1}} .
$$

The integral term included in the denominator on the right-hand side of Equation (18) is as follows:

$$
\sigma h n\left(1-b \frac{u L}{2 u_{d}(L+\delta)} \frac{\int_{0}^{L} n d x}{n}\right)=y-b \frac{u L}{2 u_{d}(L+\delta)} \int_{0}^{L} y d x .
$$

Using Equation (20), Equation (18) from 0 to $L$ and from $y_{1}$ to $y_{2}$ can be integrated as follows:

$$
\begin{aligned}
\frac{u_{d}}{v_{0}} \frac{L}{h}\left\{\frac{3(1+A R)}{2 C_{1}}\right\} & =C_{3}\left(y_{2}-y_{1}\right) \\
& +\left(1+C_{3} \frac{1+C_{4}^{2} \bar{Z}^{2}}{2}\right)\left\{\frac{1}{1+C_{4} \bar{Z}} \ln \frac{\left(y_{1}+1\right)\left(y_{2}-C_{4} \bar{z}\right)}{\left(y_{2}+1\right)\left(y_{1}-C_{4} \bar{Z}\right)}\right\} \\
& +C_{3} \frac{1-C_{4} \bar{Z}}{2} \ln \frac{\left(y_{1}+1\right)\left(y_{2}-C_{4} \bar{z}\right)}{\left(y_{2}+1\right)\left(y_{1}-C_{4} \bar{z}\right)} .
\end{aligned}
$$

where $C_{4}$ and $\bar{Z}$ are as follows:

$$
\begin{gathered}
C_{4}=b \frac{u L}{2 u_{d}(L+\delta)}, \\
\bar{Z}=\int_{0}^{L} y d x,
\end{gathered}
$$

The helix angle, channel width, channel depth, and clearance, which can improve the suction performance of the helical-grooved self-cooling case, were selected based on the above equation. The selected values are listed in Table 2. The drawing design, based on the design specifications, is shown in Figure 5.

Table 2. Helical-grooved self-cooling case parameter.

\begin{tabular}{cccc}
\hline \multicolumn{1}{c}{ Parameter } & Unit & Value \\
\hline Helix angle & $\alpha$ & $\circ$ & 10 \\
Channel width & $w$ & $\mathrm{~mm}$ & 1.5 \\
Channel depth & $h$ & $\mathrm{~mm}$ & 0.6 \\
Clearance & $\delta$ & $\mathrm{mm}$ & 0.5 \\
\hline
\end{tabular}




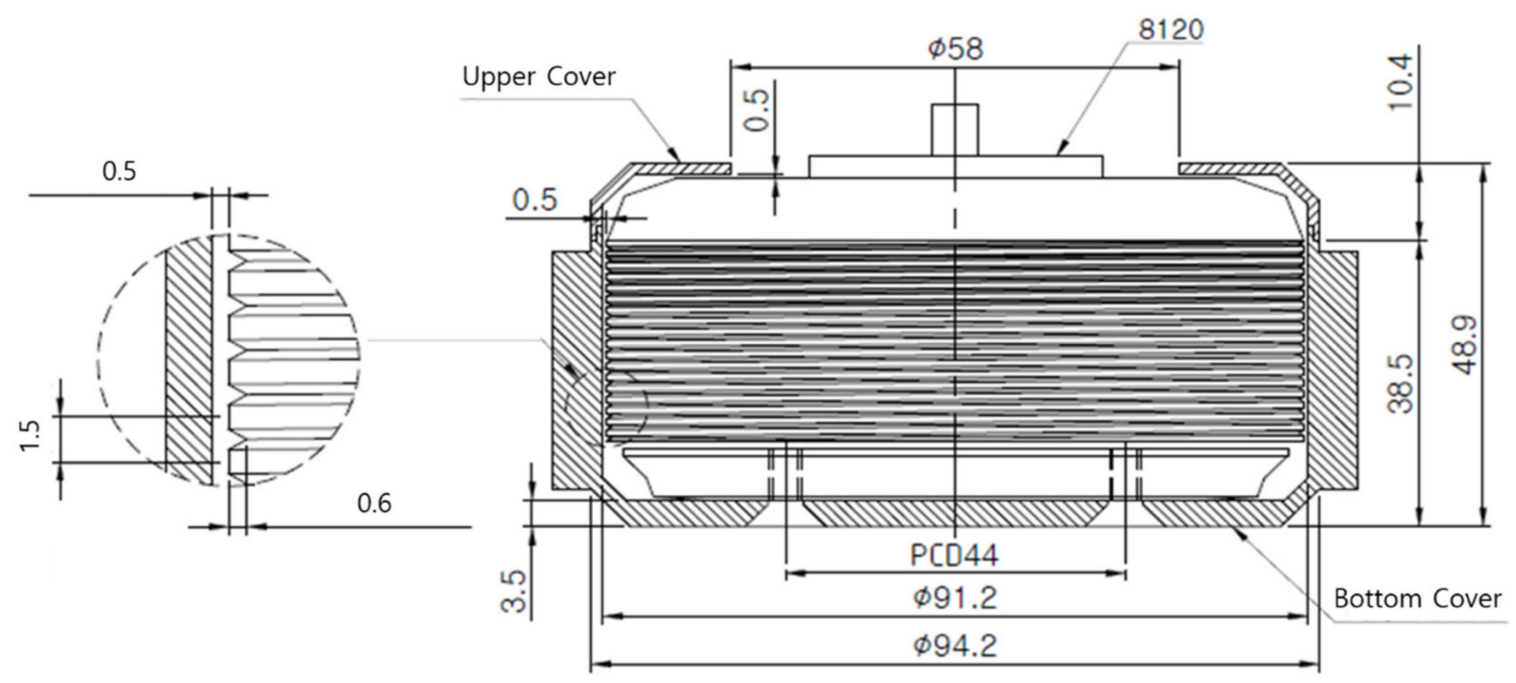

Figure 5. Drawing of the helical-grooved self-cooling case.

\section{Environment and Results of the Experiment on Heat Dissipation Characteristics \\ 5.1. Prototyping}

Figure 6 shows the design model diagram of parts that were fabricated for the experiments on heat dissipation characteristics. The stator is separated and partially designed to facilitate processing during the design process, and the magnet housing is separately designed and processed to avoid errors during magnet assembly. In addition, caution was taken when assembling because noise and product efficiency may decrease during product operation if the balance and tolerance management of the assembly equipment is not properly observed when assembling an outer motor product.

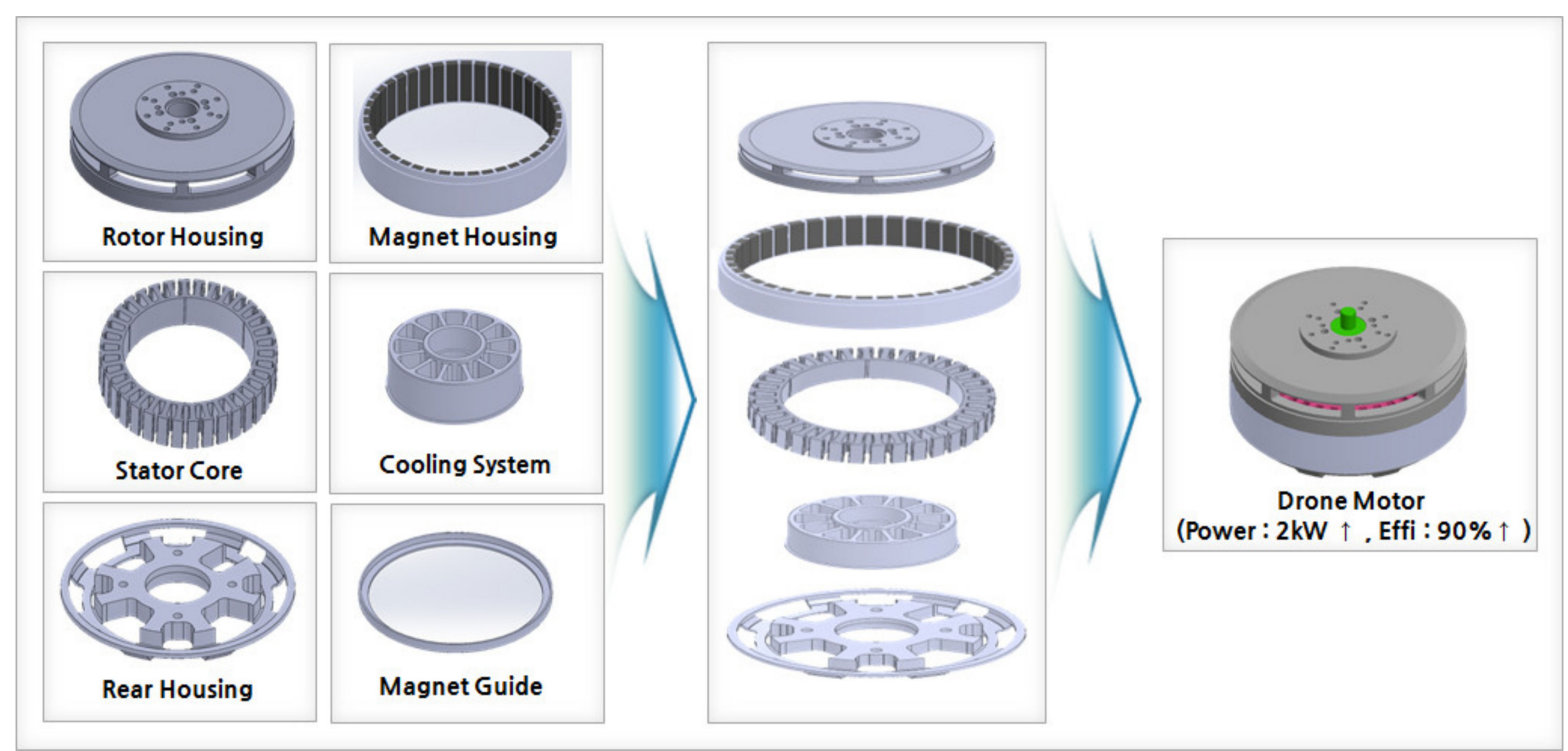

Figure 6. UAV motor prototype parts.

The stator and rotor are basically fabricated from aluminum for weight reduction in conventional mass-produced UAV motors. Nevertheless, the prototype has the advantage of weight reduction by using a magnesium alloy, and the efficiency is increased by improving the thermal characteristics. Magnesium has a specific gravity of $1.7 \mathrm{~g} / \mathrm{mL}$, which is approximately $1 \mathrm{~g} / \mathrm{mL}$ lighter than that of aluminum. It also has high strength and thermal conductivity and good electrical resistance. Moreover, it is harmless to the human 
body because it is not classified as a heavy metal, unlike aluminum. The UAV motor prototype was an IPM motor; therefore, the magnet housing, the back-yoke part, was made of SKD11, as torque and output power were increased only when there was reluctance torque due to the flux through the back yoke. The materials used for each prototype part are shown in Table 3. As shown in Figure 7, the parts were fabricated based on a 3D design drawing, which were assembled to create a prototype. Subsequently, an experiment on heat dissipation characteristics was conducted.

Table 3. Material of the prototype parts.

\begin{tabular}{|c|c|}
\hline Part & Material \\
\hline Rotor Housing and Rear Housing and Cooling Case & Magnesium Alloy $(\mathrm{Mg}+4$ wt. $\% \mathrm{Zn}+1$ wt. $\% \mathrm{Y})$ \\
\hline Magnet Housing & SKD11 \\
\hline Stator Core & $35 \mathrm{PN} 210$ \\
\hline Coil & Copper \\
\hline Permanent Magnet & N45SH \\
\hline
\end{tabular}
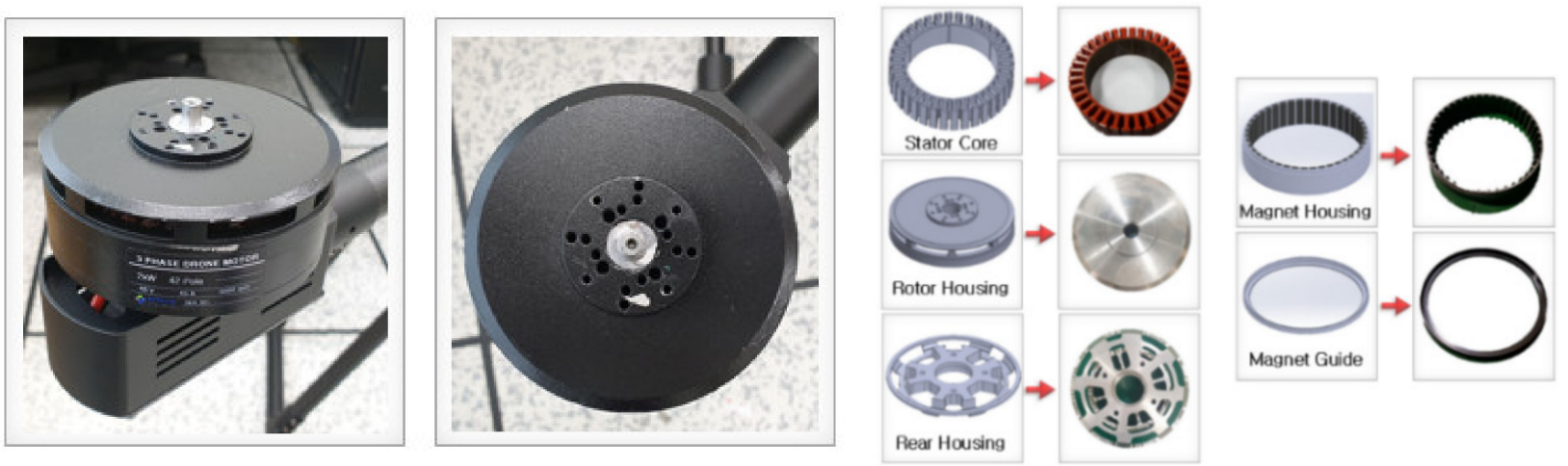

Figure 7. Prototype parts and final prototype.

\subsection{Configuration of the Heat Dissipation Characteristics Experimental Environment}

Heat dissipation performance is a significant feature of a motor. A motor generates various types of losses as it operates, acting as a heat source inside the motor and increases the temperature of the motor. Heat generation inside the motor is an essential problem that must be improved because it affects the life, efficiency, and power density of the motor. Moreover, this fact has recently been regarded as a limitation of developing high-power small motors, which are increasingly required in different industries.

Therefore, an experimental device was configured to evaluate the heat dissipation performance of the fabricated drive motor, as shown in Figure 8. First, a $44.4 \mathrm{~V}$ battery and an electronic speed controller (ESC) were connected by direct current. An environment in which a UAV motor was driven was configured by connecting the motor with a threephase ESC. Moreover, thermocouple wires were attached to seven spots, as shown in Figure 9, and the temperature of each location was measured by connecting them to the data logger, GL840. The locations of each spot are listed in Table 4. A comparative analysis was performed, measuring a conventional air-cooled UAV motor, and possible improvements were examined. 


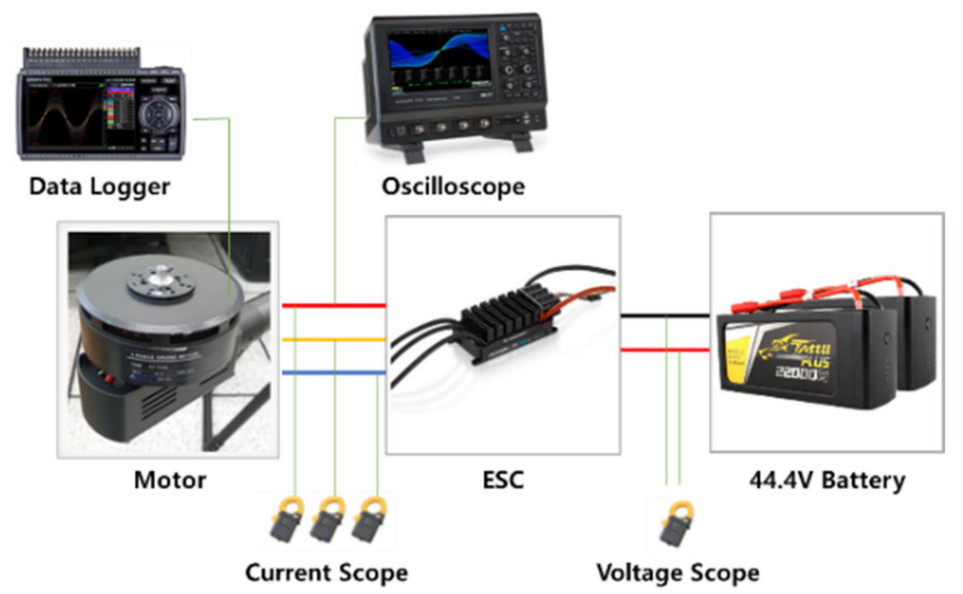

Figure 8. Configuration of the UAV motor heat dissipation characteristics experiment.

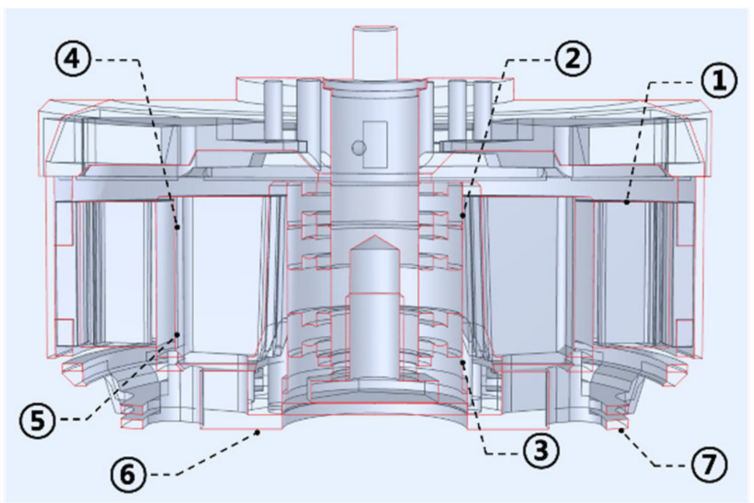

Figure 9. Thermocouple wire attachment location.

Table 4. Main parameter of the stator.

\begin{tabular}{cc}
\hline Thermocouple Wire & Location \\
\hline Spot 1 & Coil \\
Spot 2 & Top of Stator inside \\
Spot 3 & Bottom of Stator inside \\
Spot 4 & Top of Stator outside \\
Spot 5 & Bottom of Stator Outside \\
Spot 6 & Inner Bottom Cover \\
Spot 7 & Outer Bottom Cover \\
\hline
\end{tabular}

\subsection{Heat Dissipation Characteristics: Experimental Results and Comparison}

In this experiment, the temperature inside the motor and the loss of the motor were measured and examined over time while constantly rotating at a certain speed. Conventional commercial motors were also measured and tested to verify the prototype, comparing the results. The experiment was conducted under rotating at a constant speed condition of $3000 \mathrm{rpm}$ with a propeller mounted. The performance characteristics and temperature of the motor were measured at $0.5 \mathrm{~s}$ intervals. The experimental results of the heat generation characteristics with and without the helical-grooved self-cooling case on the designed and fabricated UAV motor are shown in Figures 10 and 11, respectively. The model without the water-cooled cooling structure is motor A, while the model with the structure is motor B. 


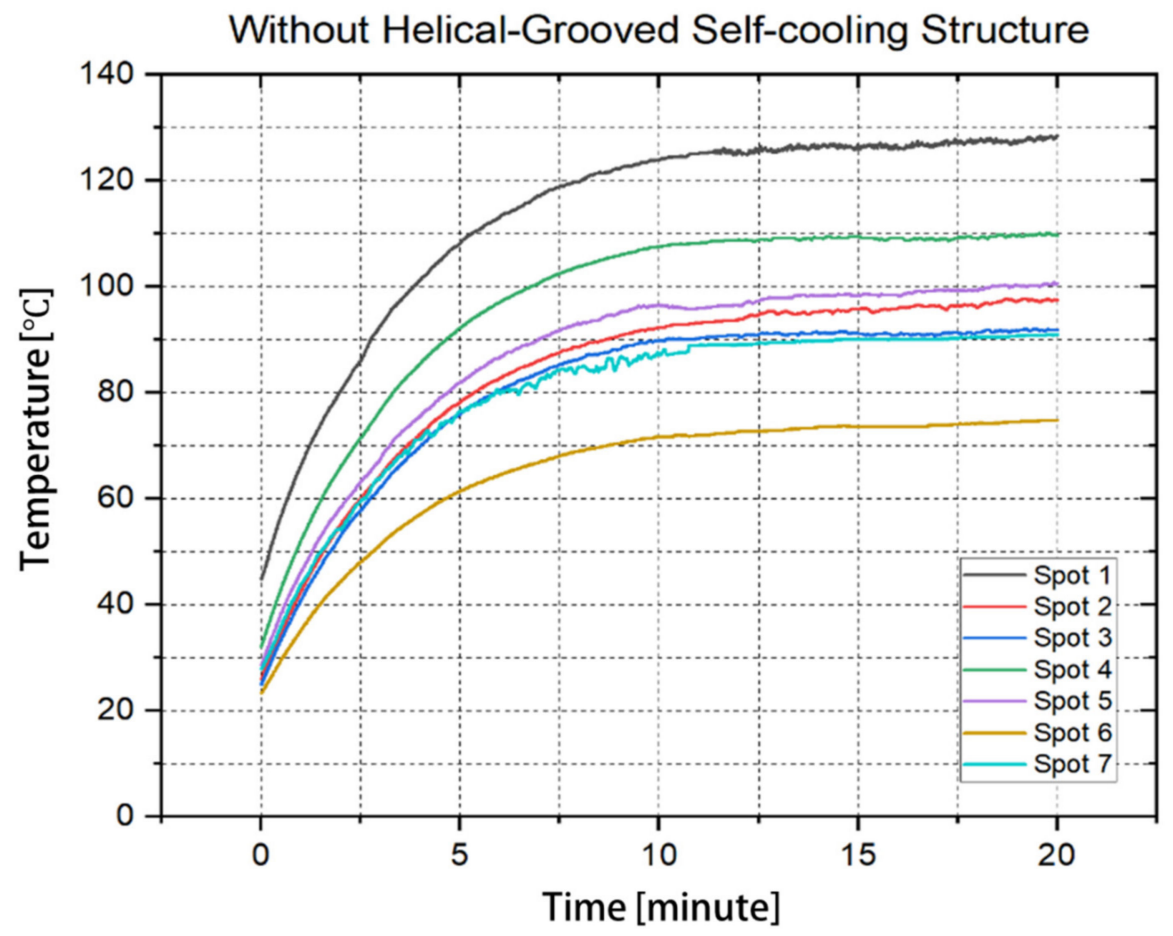

Figure 10. Heat dissipation experimental results of motor A.

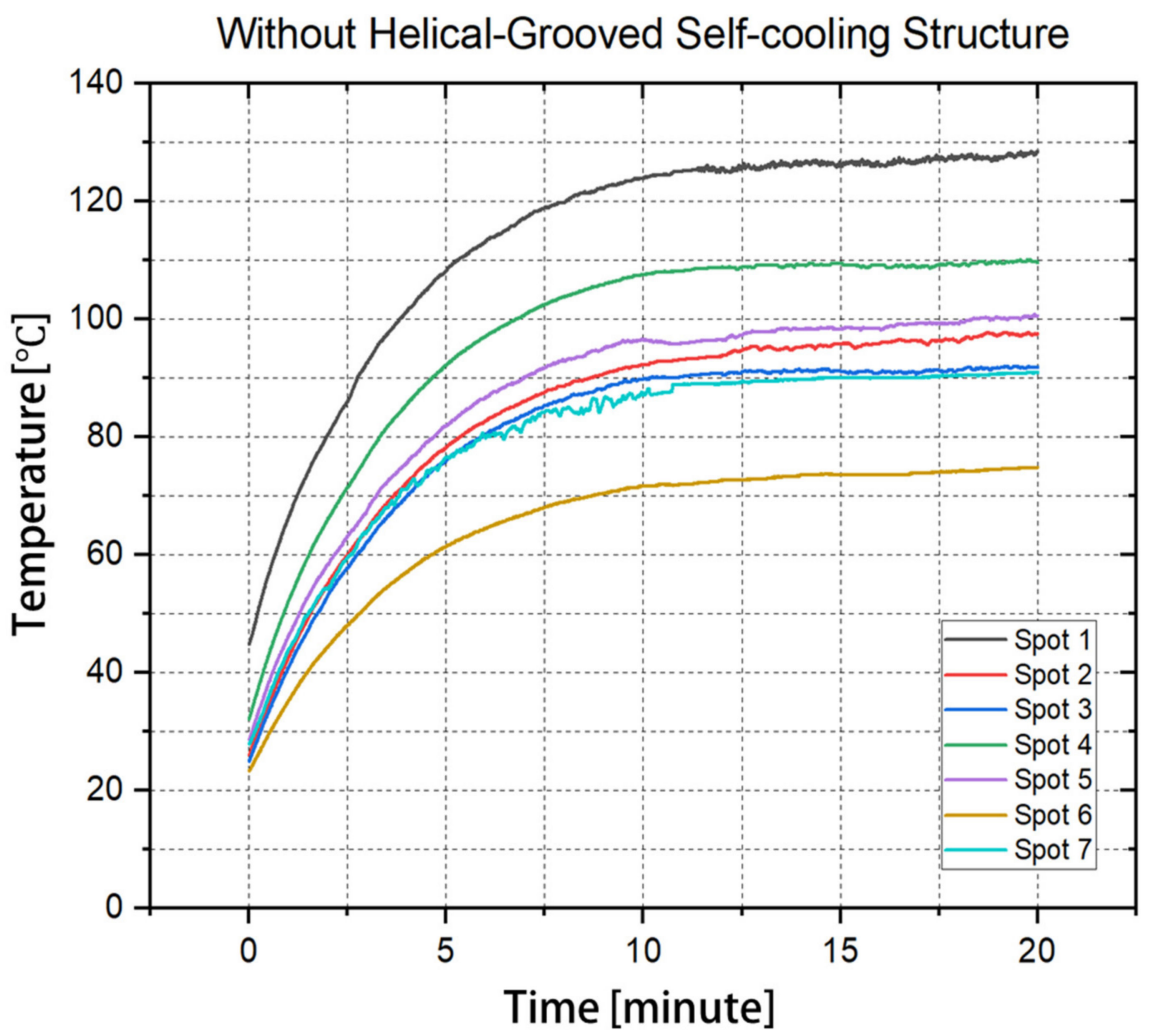

Figure 11. Heat dissipation experimental results of motor B.

The temperature distribution of the motor for each spot was $77.2-97.4{ }^{\circ} \mathrm{C}$ for motor $\mathrm{A}$, and $73.6-125.6^{\circ} \mathrm{C}$ for motor $\mathrm{B}$ when the temperature was saturated, and a particular temperature range was reached. It was found that the temperature of motor $\mathrm{B}$, where the cooling oil circulated and dissipated the generated heat, was $28.2^{\circ} \mathrm{C}$ lower than that of 
motor A, based on the maximum temperature. In particular, the temperature difference was high in the coil and stator, which are the main heat sources. Moreover, the temperature of the main heating source of motor A exceeded $100{ }^{\circ} \mathrm{C}$, while the temperature of each spot in motor B was below $100{ }^{\circ} \mathrm{C}$. Therefore, the mechanical performance of the motor and battery performance improved by dispersing the temperature of the main heat source. Demagnetization was reduced to prevent the strength of the magnetic force from deteriorating by suppressing the hot spot generation of the permanent magnet inside the rotor.

Furthermore, although the temperature was distributed in spots 1, 5, 2, 4, 3, 6, and 7 in motor A, the order was changed to spots $1,2,3,4,5,6$, and 7 in motor $\mathrm{B}$. The temperature of spots 4 and 5 near the coil decreased, thereby lowering the temperature of the stator core. This prevents damage due to a large amount of heat by the eddy current being generated in the stator core while ensuring consistently stable operability.

Figure 12 presents a comparison of the temperature values at $15 \mathrm{~min}$, which is the temperature of saturation. The temperature of the coil, which is the maximum source of heat, was $126.1^{\circ} \mathrm{C}$ for motor $\mathrm{A}$ and $95^{\circ} \mathrm{C}$ for motor $\mathrm{B}$. Thus, the temperature was reduced by $31.1^{\circ} \mathrm{C}$; moreover, the temperature decreased at all spots by an average of $11.63{ }^{\circ} \mathrm{C}$, excluding spot 6 which presented a high temperature because it was a place where cooling oil was sprayed. Therefore, the heat generated by the motor dispersed, and the total temperature inside the motor decreased.

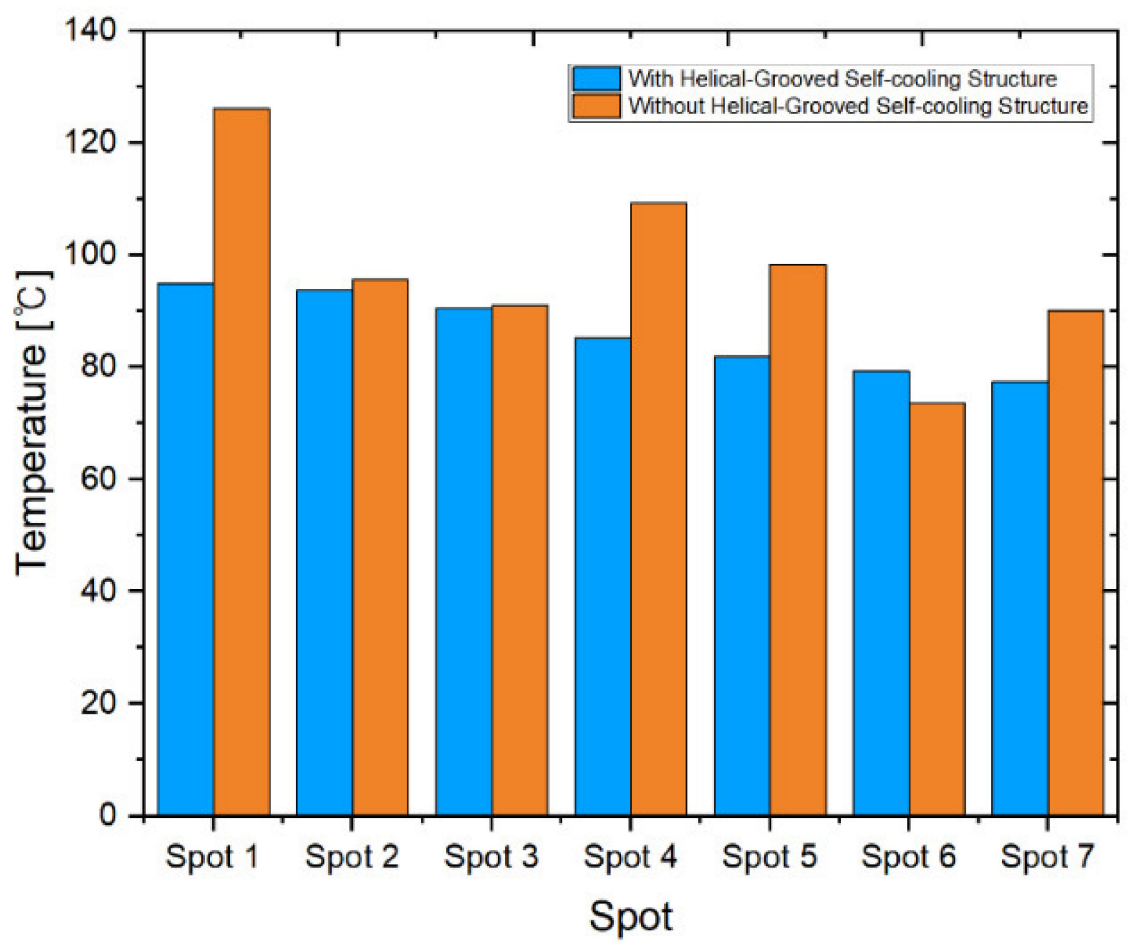

Figure 12. Temperature comparison graph for each spot at $15 \mathrm{~min}$.

Figure 13 shows a graph comparing the current while the motor was being operated, measuring at $1 \mathrm{~min}$ intervals. The temperature remained constant from 0 to $5 \mathrm{~min}$. However, there was a large deviation in the current in the subsequent section, and the maximum deviation was $3.13 \mathrm{~A}$. This is because motor A did not smoothly cool the coil and the stator core, whereas motor B maintained the strength of the magnetic force by cooling and dissipating heat. Moreover, the battery performance of motor B was also improved, because less current was required during operation compared to that of motor $\mathrm{A}$. 


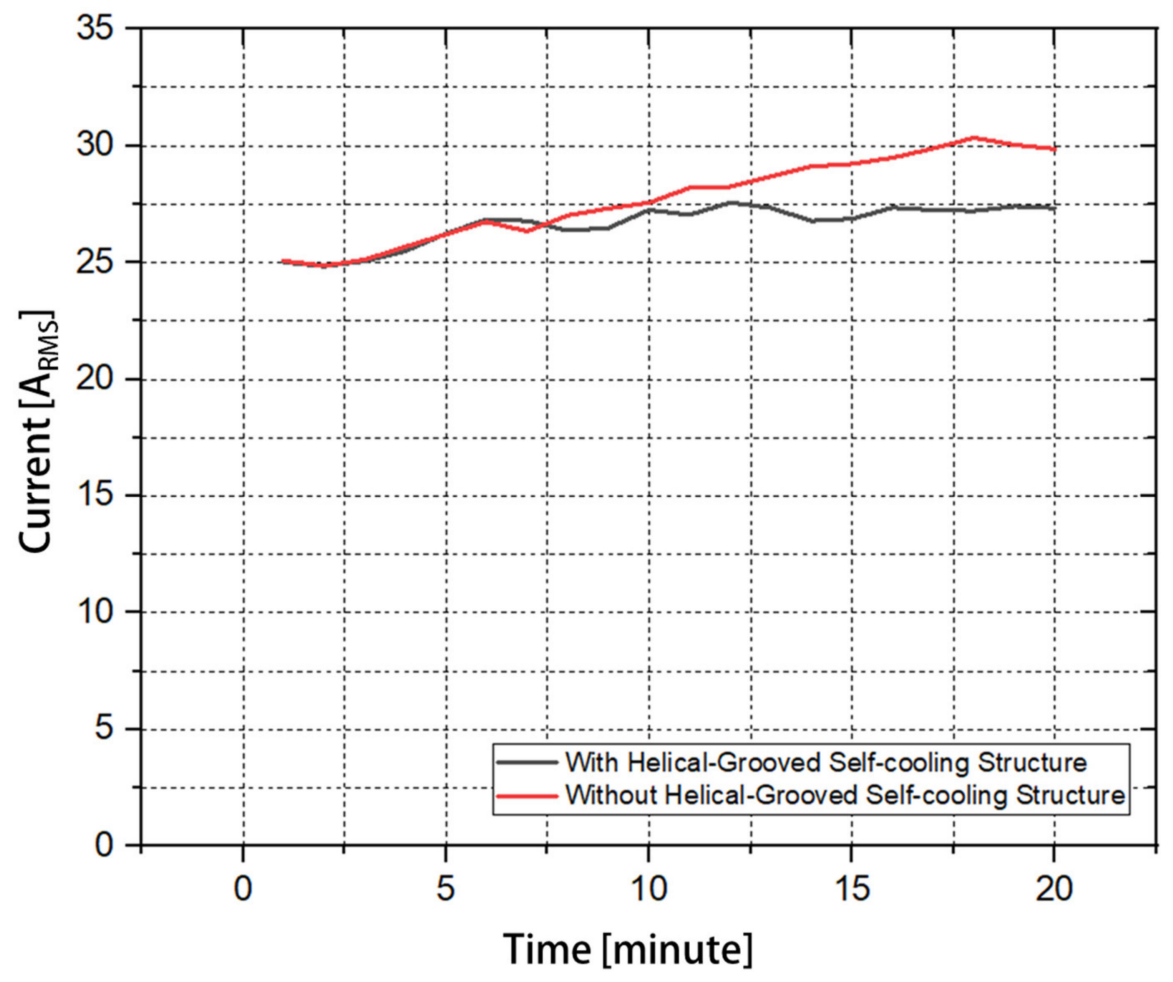

Figure 13. Motor U-phase current comparison.

\section{Conclusions}

The UAV industry is a leading business for innovative growth, because it is a convergent industry of advanced technologies such as aviation, information and communication, and software. It is changing from low-cost and small-sized vehicles for simple filming to high-priced and medium-sized vehicles for various applications such as agriculture, surveillance, surveying, and delivery. Therefore, further studies should be conducted to improve the performance of the element parts and increase flight duration.

In this study, electromagnetic field design and characteristic analysis were performed using an IPM motor instead of an SPM motor, a conventional UAV motor, by applying the finite element method to the UAV drive motor. IPM motors result in higher output power and efficiency with respect to the motor volume by using both reluctance torque and magnetic torque through phase angle control when compared to SPM motors. Therefore, an IPM motor, a high power and efficiency motor, could be applied to increase flight duration for medium- and large-sized UAVs for industrial or transportation purposes. In addition, the IPM motor was designed to ensure flight stability and performance by fabricating it in a hermetic case to prevent interference from external foreign substances during flight.

A motor with a hermetic structure requires a low heat generation design because heat dissipation is important. Therefore, the heat dissipation characteristics were analyzed by designing the helical-grooved self-cooling case of the IPM motor. The performance was verified by experimenting with the heat dissipation characteristics with the case attached to the fabricated IPM motor. According to the geometric shape of the helical groove, a performance analysis was conducted using the diffusion equation for the water-cooled case. This could reduce the weight of the UAV and improve space use by cooling the motor without requiring a separate power source.

In this study, the experiment was conducted after the case was mounted, and the results were compared with the experimental results of the conventional motor. Moreover, the thermal validity of the design was verified through the diffusion equation used. In the motor without the helical-grooved self-cooling, the temperature in each spot exceeded $100{ }^{\circ} \mathrm{C}$, and the maximum temperature was $125.6^{\circ} \mathrm{C}$. In contrast, in the motor with the helical-grooved self-cooling, each temperature was below $100{ }^{\circ} \mathrm{C}$, and the maximum 
temperature was $97.4^{\circ} \mathrm{C}$. The motor's output performance and efficiency were improved by enhancing the motor's mechanical performance and battery performance and reducing de-magnetization by suppressing the generation of hot spots of the permanent magnet inside the rotor.

The cooling performance will be improved in future work by enhancing the heat dissipation of the lower part of the case and the outer part of the stator core, where the temperature is higher than that of other spots. Further studies are also planned to be conducted on increasing flight duration and battery efficiency by performing actual flight experiments by installing the motor on a UAV.

Author Contributions: Conceptualization, H.-S.L.; data curation, M.-H.H.; formal analysis, H.-S.L.; methodology, H.-S.L.; supervision, H.-R.C.; validation, M.-H.H.; visualization, H.-S.L.; writingOriginal draft, H.-S.L.; writing-Review and editing, H.-R.C. All authors have read and agreed to the published version of the manuscript.

Funding: This study has been conducted with the support of the Korea Institute of Industrial Technology as "Development of Core Technologies for a Working Partner Robot in the Manufacturing Field"(KITECH EO-21-0004)".

Institutional Review Board Statement: Not applicable.

Informed Consent Statement: Not applicable.

Conflicts of Interest: The authors declare no conflict of interest.

\section{References}

1. Xu, X.; Deng, Y. UAV Power Component-DC Brushless Motor Design with Merging Adjacent-Disturbances and IntegratedDispatching Pigeon-Inspired Optimization. IEEE Trans. Magn. 2018, 54, 1-7. [CrossRef]

2. Gong, A.; MacNeill, R.; Verstraete, D. Performance testing and modeling of a brushless dc motor, electronic speed controller and propeller for a small uav application. In Proceedings of the 2018 Joint Propulsion Conference, Cincinnati, OH, USA, 9-11 July 2018; p. 4584.

3. Magsino, E.R.; Say, M.F.; Tan, J.A. Achieving Complete UAV Delivery in the Presence of Motor Failures. In Proceedings of the IEEE 10th Symposium on Computer Applications \& Industrial Electronics (ISCAIE), Penang, Malaysia, 18-19 April 2020; pp. 1-5.

4. Lee, K.H.; Cha, H.R.; Kim, Y.B. Development of an interior permanent magnet motor through rotor cooling for electric vehicles. Appl. Therm. Eng. 2016, 95, 348-356. [CrossRef]

5. Cho, S.K.; Jung, K.H.; Choi, J.Y. Design optimization of interior permanent magnet synchronous motor for electric compressors of air-conditioning systems mounted on EVs and HEVs. IEEE Trans. Magn. 2018, 54, 1-5. [CrossRef]

6. Zhao, N.; Schofield, N.; Hu, Y. Phase voltage distortion of IPM and SPM machines with distributed windings in field weakening region. J. Eng. 2019, 3872-3877. [CrossRef]

7. Fang, G.; Yuan, W.; Yan, Z.; Sun, Y.; Tang, Y. Thermal management integrated with three-dimensional heat pipes for air-cooled permanent magnet synchronous motor. Appl. Therm. Eng. 2019, 152, 594-604. [CrossRef]

8. Cuiping, L.I.; Zhengwei, G.U.A.N.; Junhui, L.I.; Bing, Z.; Xiucui, D.I.N.G. Optimal design of cooling system for water cooling motor used for mini electric vehicle. In Proceedings of the 20th International Conference on Electrical Machines and Systems (ICEMS), Sydney, NSW, Australia, 11-14 August 2017; pp. 1-4.

9. Guo, F.; Zhang, C. Oil-cooling method of the permanent magnet synchronous motor for electric vehicle. Energies 2019, $12,2984$. [CrossRef]

10. Ponomarev, P.; Polikarpova, M.; Pyrhönen, J. Conjugated fluid-solid heat transfer modeling of a directly-oil-cooled PMSM using CFD. In Proceedings of the International Symposium on Power Electronics Power Electronics, Electrical Drives, Automation and Motion, Sorrento, Italy, 20-22 June 2012; pp. 141-145.

11. Davin, T.; Pellé, J.; Harmand, S.; Yu, R. Experimental study of oil cooling systems for electric motors. Appl. Therm. Eng. 2015, 75, 1-13. [CrossRef]

12. Nategh, S.; Huang, Z.; Krings, A.; Wallmark, O.; Leksell, M. Thermal modeling of directly cooled electric machines using lumped parameter and limited CFD analysis. IEEE Trans. Energy Convers. 2013, 28, 979-990. [CrossRef]

13. Lim, D.H.; Kim, S.C. Thermal performance of oil spray cooling system for in-wheel motor in electric vehicles. Appl. Therm. Eng. 2014, 63, 577-587. [CrossRef]

14. Park, J.M.; Kim, K.Y.; Heo, M.W. Comparative Performance Analysis of an Electric Motor Cooling Fan with Various Inlet Vent and Blade Shapes. Int. J. Fluid Mach. Syst. 2017, 10, 394-403. [CrossRef]

15. Gai, Y.; Kimiabeigi, M.; Widmer, J.D.; Chong, Y.C.; Goss, J.; SanAndres, U.; Staton, D.A. Shaft cooling and the influence on the electromagnetic performance of traction motors. In Proceedings of the 2017 IEEE International Electric Machines and Drives Conference (IEMDC), Miami, FL, USA, 21-24 May 2017; pp. 1-6. 
16. Ai, M.; Yang, Y.; Xu, Y.; Li, Z.; Xu, L.; Wang, W. Research on Thermal Characteristics of Internal Ventilated Paths in Compact Medium High-Voltage Motor Based Fluid Network Decoupling. IEEE Access 2019, 7, 79268-79276. [CrossRef]

17. Tiwari, A.; Yavuzkurt, S. URANS Modeling of Effects of Rotation on Flow Distribution and Heat Transfer in an Electric Motor. In ASME International Mechanical Engineering Congress and Exposition; American Society of Mechanical Engineers: New York, NY, USA, 2020; Volume 84584, p. V010T10A026.

18. Kusuma, H.R.; Purwadi, A. Thermal modelling and analysis of $75 \mathrm{~kW}$ permanent magnet synchronous motor for medium bus application based on JMAG. In Proceedings of the 2017 4th International Conference on Electric Vehicular Technology (ICEVT), Bali, Indonesia, 2-5 October 2017; pp. 30-35.

19. Kang, G.H.; Hong, J.P.; Kim, G.T.; Park, J.W. Improved parameter modeling of interior permanent magnet synchronous motor based on finite element analysis. IEEE Trans. Magn. 2000, 36, 1867-1870. [CrossRef]

20. Venna, K.R.; Urbanek, H.; Anger, N. Difference between switching of motors and generators with vacuum technology. Cired-Open Access Proc. J. 2017, 1, 124-127. [CrossRef] 